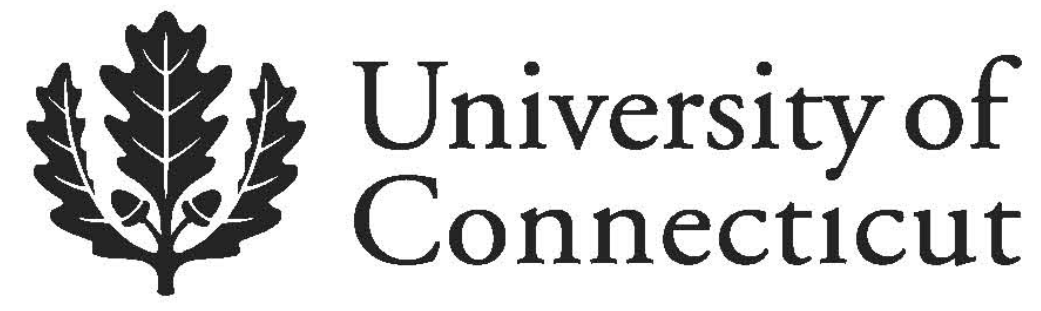

Department of Economics Working Paper Series

\title{
Do Employment Quotas Explain the Occupational Choices of Disadvantaged Minorities in India?
}

Larry L. Howard

California State University, Fullerton

Nishith Prakash

University of Connecticut, CReAM, \& IZA

Working Paper 2012-31

July 2011

365 Fairfield Way, Unit 1063

Storrs, CT 06269-1063

Phone: (860) 486-3022

Fax: (860) 486-4463

http://www.econ.uconn.edu/

This working paper is indexed on RePEc, http://repec.org 


\title{
Do Employment Quotas Explain the Occupational Choices of Disadvantaged Minorities in India?
}

\author{
Larry L. Howard ${ }^{1}$ and Nishith Prakash ${ }^{2,3}$
}

\begin{abstract}
This article investigates the effects of a large-scale public sector employment quota policy for disadvantaged minorities (Scheduled Castes and Scheduled Tribes) in India on their occupational choices, as defined by skill level, during the 1980s and 1990s. We find that, first, the employment quota policy significantly affects the occupational structure of both disadvantaged minority populations. In response to the employment quotas, individuals belonging to the Scheduled Caste group are more likely to choose high-skill occupations and less likely to choose low- and middle-skill occupations, while individuals belonging to the Scheduled Tribe group are less likely to choose high-skill occupations and more likely to choose low- and middle-skill occupations. Second, the impact of the employment quotas is significantly related with an individual's years of schooling. Overall, the results indicate that the employment quota policy changes the occupational choices of individuals within the targeted populations and contributes to their improved socio-economic standing.
\end{abstract}

JEL classification: J62, J61, J24, O10, O2.

Keywords: Affirmative Action, Employment Quota, Occupational Choice, Skill, Caste, India.

\footnotetext{
${ }^{1}$ Department of Economics, California State University, Fullerton, 800 N. State College Blvd., Fullerton, CA, 92834-6848 USA. Telephone: + 1-657-278-7171; Fax: + 1-657-278-3097; E-mail: larryhoward@fullerton.edu.

${ }^{2}$ Address for correspondence: Nishith Prakash, Department of Economics and Human Rights Institute, University of Connecticut, 341 Mansfield Rd., Storrs, CT 06269 USA. Telephone: + 1-860-486-3022; Fax: + 1-860-486-4463; E-mail: nishith.prakash@uconn.edu.

${ }^{3}$ We thank officials at the Government of India Ministry of Social Justice and Empowerment, and Scheduled Caste and Scheduled Tribe Commissioner's office in New Delhi, India for data provision and discussion, and two anonymous referees for helpful comments and suggestions on an earlier draft. The earlier version of the paper was titled "Does Employment Quota Explain Occupational Choice Among Disadvantaged Groups? A Natural Experiment from India"
} 


\section{Introduction}

Policymakers around the globe often attempt to improve the economic status of disadvantaged populations by making use of direct employment incentives commonly referred to as affirmative action policies. This research takes a first step in assessing the extent to which India's federal policy requiring states to designate a percentage of all public sector job vacancies for historically disadvantaged minorities has changed the occupational structure of the targeted populations during the 1980s and 1990s. Economists have long been concerned with the study of occupational choice due to its strong potential to affect the socio-economic status of an individual. ${ }^{1}$ While quantifying the effects of occupational choice on economic prosperity is important, there is also considerable interest in understanding the factors influencing an individual's choice. For instance, Driver (1962) and more recently Tsukahara (2007) identify the effects of family background characteristics on the subsequent occupational choices of children, Soopramanien and Johnes (2001) estimate the effects of gender on labor market participation decisions and occupational choices among individuals in the United States, Iannelli (2002) study differences in the extent to which social origin affects young people's educational and occupational outcomes in European Union countries, and Constant and Zimmermann (2003) analyze the contrast in the occupational choices of native and non-native Germans. Further, Amin (2004) estimates the impact of government affirmative action policies in Malaysia on the employment patterns of married women for three ethnic groups (the Malays, Chinese, and Indians) and finds that the policies have significantly different effects across the three groups.

In this article we provide the first estimates of the role that India's public sector employment quotas have in shaping the occupational choices, as defined by skill level, of individuals belonging to the two largest disadvantaged minority populations, the Scheduled Castes and

\footnotetext{
${ }^{1}$ See Becker (1962) and Driver (1962) for early studies.
} 
the Scheduled Tribes. ${ }^{2}$ The policy of setting employment quotas is, in general, used by the government and other institutions to help historically disadvantaged sections of society. A primary objective of this type of policy is to compensate individuals belonging to the disadvantaged group for past discrimination and subsequently increase their economic prosperity. Some economists have even suggested that "the occupational attainment of an individual will be a major determinant of their level of consumption, self-esteem, and their general status in society" (Harper and Haq, 1997). Given the importance of an individual's occupational choice in shaping their future socio-economic standing, it is of great interest to analyze the effects of a large-scale public sector employment quota policy on the occupational choices of the individuals around which the policy is designed.

Identifying the effects of affirmative action policies can be difficult because how the policies are determined and enacted is likely to be endogenous to the local environment. For instance, one can easily imagine a scenario where the institutions or locations that have affirmative action policies in place for minorities are likely to favor them in other ways too, which potentially confounds the interpretation of estimated coefficients for a regression of occupational outcomes on policy characteristics. ${ }^{3}$ In the case of India, the manner in which the public sector employment quotas are implemented facilitates the identification of its effects. According to the Constitution of India, the percentage of employment quota in each state for the Scheduled Castes and the Scheduled Tribes - the two principal historically disadvantaged populations in India - must be equal to their respective shares of a state's total population in the most recently tabulated census of the population (Prakash (2010)). This policy rule generates exogenous variation in public sector employment quota at the state level, and permits the identification of their effects on occupational choices. We are able to

\footnotetext{
${ }^{2}$ India's employment based affirmative action policy is arguably the world's largest in both its nature and coverage.

${ }^{3}$ For a detailed discussion on the issue of identification in the context of India see Prakash (2010) and (Chin and Prakash, 2010).
} 
account for intercensal fluctuations in minority population shares across states in order to avoid confounding the effects of the policy with other state-level changes that are likely to be correlated with employment opportunities. It is erroneous to expect a minority population's share to only affect occupational choices through the public sector employment quotas. Instead, our empirical strategy takes advantage of the fact that the quota levels set for the two minority groups can only change with a time lag with respect to their corresponding census and current population shares. The lag generated by the policy rule allows us to separately identify the effects of the quotas from the effects of contemporaneous changes in the respective population levels of the Scheduled Castes and the Scheduled Tribes.

We analyze the occupational structure of minorities in India using multinomial logit models that include measures of gender, educational attainment, and age as individual-level explanatory variables (Schmidt and Strauss, 1975), as well as a number of relevant characteristics of the state environments in which minorities reside and are employed. To estimate the models, we use detailed individual-level data from multiple rounds of the National Sample Survey (NSS) of India for the years 1983, 1988, 1994, and 1999, respectively. ${ }^{4}$ Our models do not require us to make an assumption about an appropriate reference point (such as average educational attainment). Instead, one of the the key advantages is that we can use individual level observations for the econometric analysis as opposed to aggregate percentages. Additionally, multinomial logit models are practical to apply in this context because they are consistent with notions of random utility maximization, easy to specify and straightforward to estimate using standard maximum likelihood procedures. ${ }^{5}$

Our main findings indicate that the occupational choices of individuals within the targeted

\footnotetext{
${ }^{4}$ The National Sample Survey Organization (NSSO), a permanent survey organization, set up in the Department of Statistics of the Government of India in 1950, collects data on various facets of the Indian economy through nationwide large-scale sample surveys to assist in socio-economic planning and policy making. We use data from the Employment and Unemployment rounds (also called Schedule 10.0) of this survey in 1983-1984 (38th round), 1987-1988 (43rd round), 1993-1994 (50th round), and 1999 (55th round).

${ }^{5}$ (Boskin, 1974); (Brown et al., 2008); (Connolly et al., 1992); (Constant and Zimmermann, 2003); (Filer, 1986); (Harper and Haq, 1997); (Hill, 1983); (McFadden and Tye, 1981); (McFadden, 1973).
} 
populations are responsive to the public sector employment quota policy. Estimation of the effects of employment quotas on the occupational structure for minorities in India should be of interest for a number of reasons. First, we are not aware of any previous study which rigorously quantifies the role of the quotas in shaping an individual's choice of occupation, as defined by skill level. Yet, this is the largest affirmative action policy in the world, and has existed for over a half century. Second, this article contributes to the literature concerned with understanding factors that have an affect on individual occupational choice in developing countries. Finally, in the context of economic development, we show that the optimal design and implementation of employment quota policies are likely to be complex as the economic incentives created by such policies are related with individual's years of schooling.

The remainder of this article proceeds as follows. Section 2 provides background information on disadvantaged minorities and the employment quota policy in India. Section 3 presents the theoretical framework and estimation strategy, while Section 4 describes the data used in our analysis. We report the main results of our study in Section 5, and conclude with a discussion of our findings in Section 6.

\section{Background}

\subsection{Caste System and Disadvantaged Minorities in India}

There are various theories behind the origin of the caste system in India, ranging from a theory of traditions to a theory of occupation. The caste system is a system of social stratification in which classes are defined by endogamous hereditary groups, often termed jatis or castes. $^{6}$ The caste system is believed to be as old as 3000 years, and consists

\footnotetext{
${ }^{6}$ The word caste or 'jati' is derived from the word 'jan', 'to be born,' and indeed the jatis are endogamous: one is born in the caste one's parents belong to; they are organized in a hierarchical way due to their status, given in terms of ritual purity, according to a continuum ranging from Brahmins (upper castes) to the
} 
of the following broad divisions (or varnas): Brahmins (Priests), Kshatriyas (Warriors), Vaisyas (Merchant), Sudras (Servants), and Scheduled Castes (outcasts, lowest menial jobs, also referred as dalits or untouchables). Another important and historically disadvantaged group, which is outside the Hindu religion and the caste system, is the Scheduled Tribes (also referred as Adivasis). Post Independence, other backward castes (OBC) is also added as a new category. The OBC category consists of castes that are just above the Scheduled Castes and largely belong to the upper sections of the Shudra category, with a few lower ranking Kshatriyas jatis being included. Each of the five caste groups are distinguished based upon their own customs and rules which define an individual's status, behavior, rituals, occupation, food, and marriage among other characteristics. ${ }^{7}$

The Indian constitution explicitly recognizes Scheduled Castes $(\mathrm{SCs})^{8}$ and Scheduled Tribes $(\mathrm{STs})^{9}$ as the two principal historically disadvantaged minority groups in India, previously known as the depressed classes. ${ }^{10}$ They together account for 24.4 percent of the total population according to the 2001 census. The SCs, who make up 16.2 percent of the total population, are comprised of groups isolated and disadvantaged by their "untouchability" status. ${ }^{11}$ The word "untouchability" refers to their low status in the traditional Hindu caste Untouchables (scheduled castes).

${ }^{7}$ Brahmins, Kshatriya, and Vaishya are considered higher in status than Shudras because adolescent males from these varnas undergo a thread ceremony making them 'twice born', a privilege not available to Shudras. Brahmins are conceptualized as being at the top of the stratification system, superseding the the Kshatriyas in spite of the latter's worldly power and wealth as the ruling caste.

${ }^{8}$ Selection criteria for Scheduled Castes: 1. Cannot be served by clean Brahmans; 2. Cannot be served by barbers, water-carriers, tailors, etc who serve the caste Hindu; 3. Pollutes a high-caste Hindu by contact or by proximity; 4 . Is one from whose hands a caste Hindu cannot take water; 5 . Is debarred from using public amenities, such as roads, ferries, wells or schools; 6 . Is debarred from the use of Temples (place of worship); 7. Will not be treated as an equal by high-caste men of the same educational qualification in ordinary social intercourse; 8. Is merely depressed on account of its own ignorance, illiteracy or poverty and, but for that, would be subject to no social disability; 9 . Is depressed on account of the occupation followed and whether, but for that, occupation it would be subject to no social disability.

${ }^{9}$ Selection criteria for Scheduled Tribes: 1. Tribal origin; 2. Primitive way of life and habitation in remote and less accessible areas; 3 . General backwardness in all respects.

${ }^{10}$ The criteria for the selection of "Scheduled Castes" and "Scheduled Tribes" groups as stated in Constitutional orders of 1950.

${ }^{11}$ The Indian Constitution prohibits the use of the word untouchability. 
hierarchy, which exposed them to invidious treatment, severe disabilities, and deprivation of economic, social, cultural, and political opportunities (Galanter, 1984). The STs, who make up 8.2 percent of the total population, are distinguished by "tribal characteristics" and by their spatial and cultural isolation from rest of the population. In addition to the aforementioned characteristics, the identity of SCs and STs is historically determined. An individual is born as a member of the SC group or ST group and cannot change his/her caste over their lifetime.

The SCs and STs in India do much worse off as compared to the non-minorities. Their poverty rate as measured by a headcount ratio is twice as high as the non-minorities. Specifically, the percentage of people below the poverty line in 1987-1988 was 55.2 in rural India and 47.1 in urban India for the SCs and 59.9 in rural India and 44.7 in urban India for the STs. Similarly, the percentage of people below the poverty line in 1999-2000 was 45.9 in rural India and 38.3 in urban India for the SCs and 36.2 in rural India and 35.6 in urban India for the STs, respectively. ${ }^{12}$ The infant mortality rate (per 1000) for the SC and ST group is 109 while for the non-SC/ST group it is $54 .{ }^{13}$ This systematic deprivation across all spheres has been the impetus for many government policies aimed at helping the SCs and STs. Among these policies is the public sector employment quota policy.

\subsection{The Public Sector Employment Quota Policy in India}

The early traces of this employment quota policy for disadvantaged minorities in public sector jobs go back to the early 1930s, under the British rule. Under the same spirit and concern, this policy found a place when the Constitution of India was being drafted after its independence in 1947 and its transition to a sovereign republic in 1950. Specifically, Articles

\footnotetext{
${ }^{12}$ Source: National Sample Survey 43rd and 55th round.

${ }^{13}$ Source: National Family Health Survey Subject Report, 1998.
} 
$16(4)^{14}, 320(4)$ and 335 of the Indian Constitution provide safeguards for SCs and STs in services and posts under the state with a view to ensuring their adequate representation in public sector jobs. The percentage of the employment quota in services/posts under the state government varies from one state to another and is fixed on the basis of the percentage of the SC and ST population relative to the total population in the respective state. ${ }^{15}$ This policy of official discrimination in favor of the worst-off sections of the population is unique in the world, both in the range of benefits involved and in the magnitude of the group members eligible for the benefits.

The National Scheduled Caste and Scheduled Tribe Commission handles the administration of the public sector employment quota policy in India. The National Commission on SC and ST has a vigorous statutory mandate and the powers of a civil court. ${ }^{16}$ This Commission co-ordinates between state governments and the federal government once the recent census population estimates by social group arrive. Before implementing the recommendation by the Commission approval from several bodies is required. After the new estimates arrive, the Commission revises the percentage of jobs reserved for SCs and STs according to the new census population estimates. Next, the Commission sends the recommendation to the President of India. Then, the Ministry of Social Justice and Empowerment places the recommendation before both houses of the Parliament, which give the final approval. Only after this set of administrative steps, the percentage of jobs reserved is revised to reflect the new census population estimates. The jumps and time lag generated by the public sector employment quota policy in India enables us to identify its effects on the occupational structure of

\footnotetext{
${ }^{14}$ Nothing in this article shall prevent the State from making any provision for the reservation of appointments or posts in favor of any backward class of citizens which in the opinion of the State, is not adequately represented in the services under the State.

${ }^{15}$ Annual Scheduled Caste and Scheduled Tribe Commissioners Report.

${ }^{16}$ Under Article 338 of the Constitution, the President of India appoints a special officer known as the commissioner for SC and ST to investigate all matters relating to the safeguards provided for the SC and ST under the various provisions of the Constitution. In 1990, through the sixty-fifth amendment of the Constitution (Article 338) the special officer was replaced by a National Commission for SC and ST with powers of a civil court to summon persons, files, etc. for securing evidence on oath.
} 
both disadvantaged minority populations.

\section{Theoretical Framework and Estimation Strategy}

A simple model of individual occupational choice helps to clarify the role that affirmative action polices can have in shaping the occupational structure of disadvantaged populations and outlines a framework for our empirical analysis. Suppose a representative individual $i$ living in state $s$ is considering a choice between different occupations that require varying skill levels $j$. The individual is assumed to have a random utility function of the form $U_{i j s}=V_{i j s}+e_{i j s}$ that comprises a deterministic component $\left(V_{i j s}, i \in I, j \in J, s \in S\right)$ representing the average utility from employment in an occupation with skill level $j$ and a nondeterministic component $\left(e_{i j s}, i \in I, j \in J, s \in S\right)$ representing random deviations from the population mean (McFadden, 1973; Manski, 1977; Hausman and Wise, 1978).

Gill (1989) applies the random utility model in the context of individual occupational choice, and we follow his general notation to the extent possible. The deterministic component of an individual's random utility function is represented as

$$
V_{i j s}=V\left(\bar{w}_{i j s}, \mathbf{X}_{i}, \mathbf{Q}_{s}\right)
$$

where $\bar{w}_{i j}$ measures the unobservable average market wage of individual $i$ in state $s$ for an occupation with skill level $j, \mathbf{X}_{i}$ is a vector of human capital and individual characteristics correlated with preferences, and $\mathbf{Q}_{s}$ is a vector of the public sector employment quota levels that are determined according to India's federal policy rule described in section 2.2. A common, convenient parametrization of the random utility function is

$$
V_{i j s}=\beta_{1} \bar{w}_{i j s}+\mathbf{X}_{i} \mathbf{B}_{1}+\mathbf{Q}_{s} \mathbf{B}_{2}+e_{i j s}
$$


with unobservable average market wages expressed as

$$
\bar{w}_{i j s}=\mathbf{X}_{i} \Theta_{1}+\mathbf{Q}_{s} \Theta_{2}+\mathbf{Z}_{s} \Theta_{3}+u_{i j s}
$$

where $\mathbf{X}_{i}$ is defined as above and $\mathbf{Z}_{s}$ is a vector of additional demographic and economic characteristics correlated with prevailing public and private employment opportunities within state $s$. Substituting equation (3) into equation (2), we write the reduced-form equation for an individual's utility function as

$$
V_{i j s}=\mathbf{X}_{i} \Gamma_{1}+\mathbf{Q}_{s} \Gamma_{2}+\mathbf{Z}_{s} \Gamma_{3}+\nu_{i j s}
$$

and random deviations from average utility across occupation skill levels are assumed to be correlated at the state level because the policy in India is directly based on previously realized state population characteristics.

Public sector employment quotas can positively affect $V_{i j s}$ by increasing the likelihood of a successful employment search for disadvantage minorities. Further, to the extent that job vacancy rates differ across occupations that require varying skill levels, the quotas can change the overall skill composition and occupational structure of the labor market. Oxoby (2008) presents a model of individual occupational choice that emphasizes the indirect influence of the previous labor market outcomes of older generations on the occupational choices of younger generations who observed the earlier outcomes. For instance, if disadvantaged minorities are uncertain about their innate ability to obtain a particular type of occupation, then they will form a probabilistic assessment of their skill level when making a choice. In determining the probability of having skill level $j$, individuals may incorporate "type-based biases" that depend on the particular minority population (type) they identify with. Oxoby (2008) shows that the bias is positively related with the observed occupational choices of the previous generation of minorities. Thus, the cumulative effect over time of the public 
sector employment quotas in India can provide incentives for minorities to disproportionately choose occupations that are similar to those chosen by the majority of minorities in previous generations. It is an empirical question as to whether the employment quota policy in India has an unequal affect on the individual choices between occupations that require varying levels of skill.

\subsection{Estimation Strategy}

To investigate the effects of India's public sector employment quota policy on individual occupational choices we consider a choice set that comprises low-, middle-, and high-skill occupations $(j=1,2,3)$. Assuming individuals choose an occupation that is associated with the highest level of utility, the probability $\left(P_{i j}\right)$ of an individual $i$ choosing an occupation with skill level $j$ is expressed as

$$
P_{i j}=\operatorname{Prob}\left(V_{i j} \geq V_{i k}\right) \quad \forall j, k \in J, j \neq k
$$

We utilize the standard multinomial logit model (MNL) specified as

$$
P_{i j}=\frac{e^{\left(\mathbf{X}_{i} \Gamma_{1 j}+\mathbf{Q}_{s} \Gamma_{2 j}+\mathbf{Z}_{s} \Gamma_{3 j}\right)}}{\sum_{k=1}^{3} e^{\left(\mathbf{X}_{i} \Gamma_{1 k}+\mathbf{Q}_{s} \Gamma_{2 k}+\mathbf{Z}_{s} \Gamma_{3 k}\right)}} \quad j=1,2,3
$$

where $i$ indexes each individual belonging to a minority population and $j$ indexes the realized choice between low, middle, and high-skill occupations, respectively. Identification of the parameters in the model requires a normalization of the coefficients and intercept to zero for one choice of occupation (Borooah, 2001), and we normalize relative to the middle-skill alternative. The validity of the strategy depends on the assumption that individuals are choosing between a low-skill and middle-skill occupation or a high-skill and middle-skill occupation, respectively; and that individuals are not choosing between low-skill and high- 
skill occupations. Given the relatively small percentage of the minority populations employed in high-skill occupations over this time period (2-3\% for SC and 1-3\% for ST), this identifying assumption regarding the margin of occupational skill that minorities are choosing between appears to be a reasonable one to make in this context.

We estimate the model in equation (6) using a pooled sample of individuals that is stratified by SC and ST affiliation. Our analytic sample is composed of employed individuals aged 18-65, living in one of the sixteen major Indian states, and not currently enrolled in school for the years 1983, 1988, 1994, and 1999. Occupations are classified by skill according to the Indian National Classification of Occupations-2004, and we describe the occupation outcomes in more detail in section 4.1 below.

The vector of explanatory variables $\mathbf{X}$ includes individual characteristics such as age, the square of age, and years of schooling. ${ }^{17}$ We further include indicator variables measuring gender, marital status, religious affiliation, and an urban location. The vector of public sector employment quotas $\mathbf{Q}_{s}$ includes the SC and ST public sector employment quotas, respectively. An individual's years of schooling are further interacted with the relevant public sector employment quota based on SC and ST affiliation to investigate potential interrelationships. The vector of state characteristics $\mathbf{Z}$ includes time varying measures of the current population shares of each of the minority groups, the census population shares of each of the minority groups, the total census population of the state, the population density of the state, the rural population share of the state, the fraction of a state's public sector employment which is age 55 to 60 , and the natural log of per capita state income lagged one year. As a final step, time fixed effects are included in the model to control for national-level changes in the occupational structure over the period 1983-1999, and a series of state-specific indicator variable are included to control for any related time-invariant characteristics of

\footnotetext{
${ }^{17}$ Years of schooling is computed by assigning 0 years for no formal education, 5 years for primary school, 10 years for secondary school, 12 years for high secondary school and 16 years for a graduate degree.
} 
states during this time.

\section{The Data}

Our empirical analysis builds on a variety of data sources that we describe in this section. The unit of analysis is an individual living in one of the sixteen major Indian states spanning the period 1983-1999, and these states account for approximately $95 \%$ of the total Indian population. ${ }^{18}$ The primary source of data is the National Sample Survey (NSS) as it provides a large, nationally representative sample of households in India. We use data from the Employment and Unemployment rounds (also called Schedule 10.0) of this survey in 1983-1984 (38th round), 1987-1988 (43rd round), 1993-1994 (50th round), and 1999 (55th round). Our analytic sample focuses on employed individuals aged 18-65, living in one of the sixteen major Indian states, and not currently enrolled in school. The Employment and Unemployment round of NSS is the only survey that collects information on individuals' earnings and labor market characteristics for the entire country. Each survey collects information on approximately 120,000 households and over half a million individuals.

\subsection{Outcome Variables}

Our occupation outcomes are constructed using the NSS Employment and Unemployment rounds. We classify occupations into the following three skill categories using the Indian National Classification of Occupations-2004 (NCO-2004) system:

Low Skill: This outcome variable is constructed for occupations with skill level I in the NCO-2004. The low skilled category consist of elementary occupations such as street vendors, shoe cleaners, domestic helpers, launderers, building caretakers, window cleaners, messen-

\footnotetext{
${ }^{18}$ The sixteen states are Andhra Pradesh, Assam, Bihar, Gujarat, Haryana, Jammu-Kashmir, Karnataka, Kerala, Madhya Pradesh, Maharashtra, Orissa, Punjab, Rajasthan, Tamil Nadu, Uttar Pradesh and West Bengal.
} 
gers, porters, door keepers, garbage collectors, agricultural fishery labourers, mining and construction labourers, manufacturing labourers, transport labourers and freight handlers.

Middle Skill: This outcome variable is constructed for occupations with skill level II in the NCO-2004. The middle skilled category consist of occupations such as secretaries, office clerks, cashiers, travel attendants and guides, house keeping and restaurant services workers, protective services workers, shop salespersons, stall and market salespersons, market gardeners, crop growers, animal producers, forestry and fishery workers, hunters, trappers, miners, stone cutters and carvers, building finishers, painters, welders, sheet metal workers, blacksmiths, tool makers, machinery mechanics and fitters, plant and machine operators, locomotive engine drivers, motor vehicle drivers, and ships' deck crews.

High Skill: This outcome variable is constructed for occupations with skill level III and IV in the NCO-2004. The high skilled category consist of occupations such as physicists, chemists, mathematicians, statisticians, computing professionals, architects, engineers, health and nursing professionals, secondary education teaching professionals, legal professionals, archivists, librarians, computer associate professionals, optical and electronic equipment operators, ship and aircraft controllers and technicians, health and nursing associate professionals, middle and primary education teaching associate professionals, finance and sales associate professionals, and police inspectors and detectives.

\subsection{Policy and Control Variables}

This article uses the Scheduled Caste and Scheduled Tribe Annual Commissioner's Report (1951-2000) to obtain the public sector employment quota measures for SCs and STs. The institutional details for the employment quota policy also comes from this report. This is a state level database available for the period 1951-2000. The variables are referred to as the "SC public sector employment quota" and the "ST public sector employment quota," and measure the public sector employment quota for the SCs (STs) in a state in any given year. 
The NSS described previously is an individual-level database while the policy variables we focus on are at the state-time level. These policy variables, and additional control variables for the state environment, are merged with the NSS individual-level data by state and year.

The state population data come from the Census of India, Registrar General data from 1981-2001. We use "SC (ST) current population share" which is the SC (ST) population share from the census as measured in the current year and "SC (ST) census population share" which is the SC (ST) population share from the last tabulated census. Population density is computed as the ratio of the total population from the census as measured when reservation was determined in the state to the total land area of the state, as reported in the Census Atlas, India. This variable is also updated according to the two conditions described above.

The individual level control variables are extracted from the NSS. They include an individual's age, gender, caste, and marital status. Years of school is computed by assigning 0 years for no formal education, 5 years for primary school, 10 years for secondary school, 12 years for high secondary school and 16 years for a graduate degree. We also form the variable "Fraction of elderly people in public sector employment". This variable is constructed using the NSS as the total number of people between age 55-60 in the public sector employment divided by total public sector employment times 100, and captures state variation in share of elderly people in a public sector job over time. If there is a higher share of such people then this could have a direct effect on potential job vacancies in the public sector. Lastly, for the state income measure we use the logarithm of real per capita net state domestic product in the previous year. These data come from the Domestic Product of States of India from 1983 to 2000 prepared by Economic and Political Weekly Research Foundation. 


\section{Results}

\subsection{The Effects of Public Sector Employment Quotas on the Oc- cupational Choices of the SC population}

Table 1 presents the predicted average marginal effects of the public sector employment quota policy and characteristics of individuals and states on the probability of low-, middleand high-skill occupational employment for the Scheduled Castes. ${ }^{19}$ We find that the SC public sector employment quota does not affect the likelihood of an SC member choosing to be in a low- or middle-skill occupation, on average, as the reported marginal effects are not significant at conventional levels. Although we do not find a statistically significant effect of SC employment quota on the choice of low- and middle-skill occupations, the sign is positive (0.0072) for the middle-skill category and negative for the low-skill category (-0.0099). One potential explanation of the results is that members of the SC group are well represented in these occupations already and we fail to detect any precise effect at the margin. Nonetheless, it does not mean that the policy is having no or a negative impact on probability of lowand middle-skill occupational employment for SCs. Another possible explanation behind the results can be derived from a spatial mismatch story. This is especially true for low-skill occupational employment. The marginal effect for the urban sector dummy is negative and significant and reflects the fact that a large share of low-skill jobs in India are located in rural areas, while the SCs are typically located in urban areas.

For high-skill occupations, we find that the SC public sector employment quota positively changes the likelihood of an SC member choosing an occupation in this category. The

\footnotetext{
${ }^{19}$ The marginal effects reported in Table 1 are based on coefficient estimates from the multinomial logit model specified in equation 6, and these results are reported in Appendix Table A3. While it is possible for the iterative fitting procedure used to estimate multinomial logit models not to converge in some cases, our particular application of the model for the SCs converged after five iterations using the Stata mlogit procedure (version 11; StataCorp LP; College Station, TX, USA); non-convergence was unlikely to occur in this case given our large sample size of 202,945 observations.
} 
reported marginal effect $(0.0027)$ is statistically significant. This is an important result as the SC public sector employment quota policy is motivating one of the most disadvantaged minority populations to choose high-skill jobs. This will likely have a far reaching impact on their short- and long-run socio-economic standing. A potential explanation for why we detect a positive and significant effect can be drawn from the reported marginal effect for the urban sector dummy; this effect is positive and significant and suggests that SC group members are able to obtain high skill jobs because such jobs are more likely to be available in urban areas.

Table 2 reports the predicted average marginal effects of the SC public sector employment quota on the probability of low-, middle-, and high-skill occupational employment by years of schooling. The results suggest that having completed more years of schooling magnifies the impact of the employment quota on high-skill occupational employment. It is comforting to find that the magnitude of the marginal effect increases with additional years of schooling. There are two possible explanations for this relationship. First, more years of schooling reflects higher ability. Second, the share of SC members who complete more than 10 years of schooling is very low (the mean is 2.6 in 1999) and hence our estimated effects could reflect less competition among the elite SC members. ${ }^{20}$ Overall, the percentage of individual occupational choices predicted by our model that were in fact correct is high at $63 \%$ for the SCs.

\subsection{The Effects of Public Sector Employment Quotas on the Oc- cupational Choices of the ST population}

Table 3 presents the predicted average marginal effects of the public sector employment quota policy and characteristics of individuals and states on the probability of low-, middle-

\footnotetext{
${ }^{20}$ However, to estimate this precise effect is beyond the scope of the current study.
} 
and high-skill occupational employment for the Scheduled Tribes. ${ }^{21}$ We find that the ST public sector employment quota does not change the likelihood of an ST member choosing to be in a low- or middle-skill occupation, on average, as the reported marginal effects are not significant at conventional levels. Although we do not find a statistically significant effect of ST employment quota on the choice of low- and middle-skill occupations, the sign is negative $(-0.0044)$ for the middle-skill category and positive for the low-skill category (0.0078). There are a few potential explanations behind this interesting result. First, ST members are a tribal population who reside in geographically isolated areas, and these areas are the not typically where the majority of the employment opportunities are. This is especially true for middleand high-skilled occupations. However, low-skill occupations include street vendors, shoe cleaners, domestic helpers etc. and such jobs remain available in rural and geographically isolated locations, albeit at a lower absolute level relative to urban areas. ${ }^{22}$ So it is intuitive to expect the sign of the effect to be positive for the STs. Second, this result is supported by the findings of Prakash (2010), who estimates the impact of the same employment quota policy on general labor market outcomes. His results suggest that there was no impact of the policy on ST's labor market outcomes, especially employment outcomes. So it is not surprising that we do not detect any significant effect for low- and middle-skill occupational employment, on average.

For high-skill occupations, we find that the ST public sector employment quota negatively changes the likelihood of an ST member choosing an occupation in this category. The reported marginal effect $(-0.0034)$ is statistically significant. This effect is a counter intuitive result, but considering that the share of ST members who have obtained the required

\footnotetext{
${ }^{21}$ The marginal effects reported in Table 3 are based on coefficient estimates from the multinomial logit model specified in equation 6, and these results are reported in Appendix Table A4. While it is possible for the iterative fitting procedure used to estimate multinomial logit models not to converge in some cases, our particular application of the model for the STs converged after seven iterations using the Stata mlogit procedure (version 11; StataCorp LP; College Station, TX, USA); non-convergence was unlikely to occur in this case given our large sample size of 110,295 observations.

${ }^{22}$ Section 4 describes the occupational outcome variables and the jobs included in each category in detail.
} 
educational qualification to compete for high-skill occupational employment together with the mixed empirical evidence of labor market discrimination in India, this is perhaps to be expected. ${ }^{23}$ However, we need to keep in mind that our definition of high-skill occupational employment mainly includes public sector jobs and not private sector jobs.

Table 4 reports the predicted average marginal effects of the ST public sector employment quota on the probability of low-, middle-, and high-skill occupational employment by years of schooling. The results suggest that having completed more years of schooling magnifies the impact of the employment quota on high-skill occupational employment. This result is consistent because a small number of STs complete more than 10 years of school, and once they meet the educational qualification there is less competition among STs for low- and middle-skill occupations. Additionally, evidence of labor market discrimination is detected in the white collared jobs (i.e. high-skill occupational employment). For high-skill occupations, the estimated effects suggest that having completed more years of schooling increases the negative impact of the employment quota. This relationship is possible because, as we discussed above, there is evidence of labor market discrimination in private sector jobs (Banerjee et al., 2009; Siddique, 2011). It is especially true for ST members with more years of schooling completed (the majority of private sector jobs require a minimum of 12 years of schooling completed). Overall, the percentage of individual occupational choices predicted

\footnotetext{
${ }^{23}$ Siddique (2011) uses an audit study to determine the extent of caste-based discrimination in the Indian private sector. On average low-caste applicants need to send 20 percent more resumes than high-caste applicants to get the same callback. Differences in callback which favor high-caste applicants are particularly large when hiring is done by male recruiters or by Hindu recruiters. This finding provides evidence that differences in callback between high and low-caste applicants are not entirely due to statistical discrimination. High-caste applicants are also differentially favored by firms with a smaller scale of operations, while low-caste applicants are favored by firms with a larger scale of operations. However, in contrast, Banerjee et al. (2009) study the role of caste and religion in India's new economy sectors-software and call-centers-by sending 3160 fictitious resumes in response to 371 job openings in and around Delhi (India) that were advertised in major city papers and online job sites. They randomly allocate caste-linked surnames across resumes in order to isolate the effect of caste on applicants' job-search outcomes. They find no evidence of discrimination against non-upper-caste (i.e. Scheduled Castes, Scheduled Tribes, and Other Backward Caste) applicants for software jobs. They do find large and significant differences between callback rates for upper-castes and Other Backward Castes (and to a lesser extent Scheduled Castes) in the case of call-center jobs.
} 
by our model that were in fact correct is high at $62 \%$ for the STs.

\section{Discussion}

In this study, we provide the first estimates of how India's federal affirmative action policy requiring states to designate a percentage of all public sector job vacancies for the Scheduled Castes and Scheduled Tribes has changed the occupational structure, as defined by skill level, of the targeted minority populations during the 1980s and 1990s. The fundamental assumption underlying our empirical strategy is that individuals choosing between occupations which require high- or middle-skill levels do not respond to occupational attributes specific to alternative low-skill occupations. Similarly, those choosing between occupations which require low- or middle-skill levels are not responsive to attributes of alternative high-skill occupations. Given the relatively small percentage of minorities employed in high-skill occupations over this time period (2-3\% for SCs and 1-3\% for STs), this identifying assumption regarding the margin of occupational skill that minorities are choosing between appears to be a reasonable one to make in this context. Overall, the results indicate that the employment quota policy significantly affects the occupational choices of individuals within the targeted populations.

On average, we find that the employment quotas have unequal effects on the overall occupational structure of each minority population. The SCs are more likely to choose highskill occupations, and the STs are less likely to choose high-skill occupations. While the results are consistent with the fact that STs tend to live in geographically isolated areas where high-skill employment opportunities are scarce, we find additional evidence that the employment quotas targeting the SC population also decrease the probability of STs choosing such occupations. This estimated cross-effect suggests a degree of competition between the two populations for high-skill employment opportunities, and that STs are possibly subject 
to greater labor market discrimination for these occupations. Policymakers do not typically address the potential for negative externalities in the design of affirmative action policies that target multiple minority populations, and the findings here indicate that improvements in occupational attainment for one minority population may come at the expense of another.

Furthermore, we uncover evidence that the impact of the employment quotas is significantly related with an individual's years of schooling. In general, the marginal effects become larger in magnitude as an individual acquires additional education, and a simple evaluation of the effects at the sample mean fails to reveal changes in the overall occupational structure of the minority populations. For instance, while the employment quotas targeting the SC population increase the probability of SCs choosing high-skill occupations at all education levels, we find that they also significantly decrease the probability of SCs choosing both low- and middle-skill occupations for those with 12 or more years of schooling. Similarly, while the employment quotas targeting the ST population decrease the probability of STs choosing high-skill occupations at all education levels, we find that they also significantly increase the probability of STs choosing both low- and middle-skill occupations for those with 16 years of schooling. In the context of economic development, the findings indicate that the optimal design and implementation of employment quota policies are complex as the economic incentives created by such policies are likely to depend on a combination of individual and environmental characteristics, particularly educational attainment and the geographical location of employment opportunities.

From a policy perspective, our findings are particularly important if we believe that occupational choice is correlated with socio-economic standing in society. Here, we see that schooling levels are a strong predictor of occupational choice; however, we also see that individuals with more schooling are more responsive to the policy. So to one extent we can attribute part of the improved socio-economic condition of the minority populations to the employment quotas. However, some caution is required in considering the effectiveness of 
such policies from a development standpoint. Our results suggest that policymakers need to incorporate the spatial distribution of employment opportunities relative to the locations of minorities within states if they intend to change the magnitude of the effects of this particular type of affirmative action policy. More research along these lines would likely prove informative for understanding how employment quotas change the economic incentives for minority populations. 


\section{References}

Amin, S., 2004. Ethnic differences and married women's employment in malaysia: do government policies matter? Journal of Socio-Economics 33 (3), 291-306.

Banerjee, A., Bertrand, M., Datta, S., Mullainathan, S., 2009. Labor market discrimination in delhi: Evidence from a field experiment. Journal of Comparative Economics 37 (1), 14-27.

Becker, G. S., 1962. Discrimination and the occupational progress of negroes: a comment. The Review of Economics and Statistics 44 (2), 214-215.

Borooah, V., 2001. Logit and probit: Ordered and multinomial models. Sage University Papers Series on Quantitative Applications in the Social Sciences, 07-138, Thousand Oaks, CA.

Boskin, M. J., Part I, M 1974. A conditional logit model of occupational choice. Journal of Political Economy 82 (2), 389-98.

Brown, S., Fry, T. R., Harris, M. N., May 2008. Untangling supply and demand in occupational choice. Economics Letters 99 (2), 414-417.

Chin, A., Prakash, N., 2010. The redistributive effects of political reservation for minorities: Evidence from india. forthcoming in Journal of Development Economics.

Connolly, S., Micklewright, J., Nickell, S., July 1992. The occupational success of young men who left school at sixteen. Oxford Economic Papers 44 (3), 460-79.

Constant, A., Zimmermann, K. F., 2003. Occupational choice across generations. SSRN eLibrary. 
Driver, E. D., 1962. Caste and occupational structure in central india. Social Forces 41 (1), $26-31$.

Filer, R. K., April 1986. The role of personality and tastes in determining occupational structure. Industrial and Labor Relations Review 39 (3), 412-424.

Galanter, M., 1984. Competing equalities: Law and the Backward Classes in India. University of California Press, Berkeley, CA.

Gill, A. M., 1989. The role of discrimination in determining occupational structure. Industrial and Labor Relations Review 42 (4), 610-623.

Harper, B., Haq, M., 1997. Occupational attainment of men in britain. Oxford Economic Papers 49, 638-650.

Hausman, J. A., Wise, D. A., 1978. A conditional probit model for qualitative choice: Discrete decisions recognizing interdependence and heterogeneous preferences. Econometrica $46(2), 403-426$.

Hill, A., 1983. Female labor force participation in developing and developed countries- consideration of the informal sector. Review of Economics and Statistics 65 (3), 459-468.

Iannelli, C., Jul 2002. Parental education and young people's educational and labour market outcomes: A comparison across europe. MZES Working Papers 45, MZES.

Manski, C. F., 1977. The structure of random utility models. Theory and Decision 8 (3), $229-254$.

McFadden, D., 1973. Conditional logit analysis of quantitative choice behavior. Frontiers of econometrics, New York: Academic Press, 105-142. 
McFadden, D, T. K., Tye, W., 1981. An application of diagnostic tests for the independence from irrelevant alternative property of the multinomial logit model. Transportation Research Record 637, 39-46.

Oxoby, R. J., 2008. Skill uncertainty and social inference. Labour Economics 15 (3), 400-405.

Prakash, N., 2010. The impact of employment quotas on the economic lives of disadvantaged minorities in india. Cornell University mimeo.

Schmidt, P., Strauss, R. P., 1975. The prediction of occupation using multiple logit models. International Economic Review 16 (2), 471-486.

Siddique, Z., 2011. Evidence on caste-based discrimination. forthcoming in Labour Economics.

Soopramanien, D., Johnes, G., 2001. A new look at gender effects in participation and occupation choice. LABOUR 15 (3), 415-443.

Tsukahara, I., 2007. The effect of family background on occupational choice. LABOUR $21(4-5), 871-890$. 
Table 1: The predicted average marginal effects of public sector employment quotas and characteristics of Scheduled Caste individuals and states on the probability of low-, middle-, and high-skill occupational employment ${ }^{\mathrm{a}}$

\begin{tabular}{lcccccc}
\hline & \multicolumn{5}{c}{ Probability of Scheduled Castes occupational skill level } \\
\cline { 2 - 7 } & \multicolumn{2}{c}{ Low } & \multicolumn{2}{c}{ Middle } & High \\
\cline { 2 - 7 } Explanatory variable & dy/dx & SE & dy/dx & SE & dy/dx & SE \\
\hline & -0.0099 & 0.0067 & 0.0072 & 0.0060 & $0.0027^{* *}$ & 0.0011 \\
SC public sector employment quota & & & & & & \\
& $-0.0295^{* *}$ & 0.0012 & $0.0232^{* *}$ & 0.0012 & $0.0063^{* *}$ & 0.0001 \\
Years of schooling & $-0.0025^{* *}$ & 0.0004 & $0.0020^{* *}$ & 0.0004 & $0.0006^{* *}$ & 0.0000 \\
Age & $-0.0684^{* *}$ & 0.0127 & $0.0796^{* *}$ & 0.0135 & $-0.0111^{* *}$ & 0.0022 \\
Male & $0.0380^{* *}$ & 0.0127 & $-0.0336^{* *}$ & 0.0118 & $-0.0044^{* *}$ & 0.0018 \\
Married & $-0.1223^{* *}$ & 0.0303 & $0.1058^{* *}$ & 0.0321 & $0.0165^{* *}$ & 0.0057 \\
Muslim religion b & 0.0155 & 0.0215 & -0.0191 & 0.0199 & 0.0036 & 0.0027 \\
Other religion b & $-0.0991^{* *}$ & 0.0273 & $0.0894^{* *}$ & 0.0271 & $0.0097^{* *}$ & 0.0013 \\
Urban sector & & & & & & \\
& & & & & & \\
SC current year population share & 0.0001 & 0.0066 & 0.0024 & 0.0065 & $-0.0025^{* *}$ & 0.0009 \\
SC census population share & 0.0053 & 0.0103 & -0.0082 & 0.0099 & $0.0029^{*}$ & 0.0015 \\
ST public sector employment quota & -0.0017 & 0.0058 & 0.0002 & 0.0050 & 0.0015 & 0.0010 \\
ST current year population share & 0.0382 & 0.0237 & -0.0345 & 0.0222 & -0.0037 & 0.0034 \\
ST census population share & -0.0044 & 0.0288 & -0.0005 & 0.0270 & 0.0049 & 0.0051 \\
Total census population & $0.0000^{* *}$ & 0.0000 & $-0.0000^{* *}$ & 0.0000 & -0.0000 & 0.0000 \\
Population density & 0.0001 & 0.0002 & -0.0001 & 0.0002 & 0.0000 & 0.0000 \\
Rural population share & $-0.0088^{* *}$ & 0.0037 & $0.0073^{* *}$ & 0.0034 & $0.0015^{* *}$ & 0.0007 \\
Public sector employees age 55-60 & $-0.0047^{* *}$ & 0.0021 & $0.0049^{* *}$ & 0.0021 & -0.0002 & 0.0004 \\
Ln(state income per capita in previous year) & $-0.0305^{* *}$ & 0.0092 & $0.0276^{* *}$ & 0.0086 & 0.0029 & 0.0020
\end{tabular}

Notes: Marginal effects (dy/dx) of the explanatory variables on the probability of choosing high-, middle-, and lowskill occupations and standard errors are reported. The marginal effects are based on coefficient estimates from multinomial logit model, which are reported in Appendix Table A3, and the standard errors were adjusted for within state correlation across the four survey rounds. The total number of observations in the Scheduled Castes sample is 202,945. Occupational skill is classified according to the 2004 National Classification of Occupations (NCO-2004); high-skilled occupations include professionals and associate professionals; middle-skill occupations include clerks, service workers, shop and market sale workers, agricultural and fishery workers, craft and related trades workers, and plant and machine operators and assemblers; low-skilled occupations include elementary occupations. See section 4.1 for more information on the specific occupations included in each skill category.

** Significant at 5-percent level; * Significant at 10-percent level.

a SC and ST indicate the populations of the Scheduled Castes and Scheduled Tribes, respectively.

${ }^{b}$ Hinduism is the reference category for religious affiliation. 
Table 2: The predicted average marginal effects of public sector employment quotas on the probability of low-, middle-, and high-skill occupational employment of the Scheduled Castes by years of schooling ${ }^{\text {a }}$

Probability of Scheduled Castes occupational skill level

SC public sector employment quota $X$ Years of schooling:

\begin{tabular}{ccrccc}
\hline Low & \multicolumn{4}{c}{ Middle } & \multicolumn{2}{c}{ High } \\
\hline \multicolumn{1}{c}{$\mathrm{dy} / \mathrm{dx}$} & $\mathrm{SE}$ & $\mathrm{dy} / \mathrm{dx}$ & $\mathrm{SE}$ & $\mathrm{dy} / \mathrm{dx}$ & $\mathrm{SE}$ \\
& & & & & \\
$-0.0131^{*}$ & 0.0070 & 0.0059 & 0.0051 & $0.0072^{* *}$ & 0.0028 \\
$-0.0152^{* *}$ & 0.0067 & -0.0058 & 0.0036 & $0.0210^{* *}$ & 0.0083 \\
$-0.0140^{* *}$ & 0.0059 & $-0.0115^{* *}$ & 0.0051 & $0.0254^{* *}$ & 0.0101 \\
$-0.0081^{* *}$ & 0.0034 & $-0.0157^{* *}$ & 0.0068 & $0.0238^{* *}$ & 0.0100
\end{tabular}

Notes: Marginal effects (dy/dx) of public sector employment quota on the probability of choosing high-, middle-, and low-skill occupations by years of schooling and standard errors are reported. The marginal effects are based on coefficient estimates from multinomial logit model, which are reported in Appendix Table A3, and the standard errors were adjusted for within state correlation across the four survey rounds. The total number of observations in the Scheduled Castes sample is 202,945. Occupational skill is classified according to the 2004 National Classification of Occupations (NCO-2004); high-skilled occupations include professionals and associate professionals; middle-skill occupations include clerks, service workers, shop and market sale workers, agricultural and fishery workers, craft and related trades workers, and plant and machine operators and assemblers; low-skilled occupations include elementary occupations. See section 4.1 for more information on the specific occupations included in each skill category. ** Significant at 5-percent level; * Significant at 10-percent level.

${ }^{\mathrm{a}} \mathrm{SC}$ indicates the population of the Scheduled Castes. 
Table 3: The predicted average marginal effects of public sector employment quotas and characteristics of Scheduled Tribe individuals and states on the probability of low-, middle-, and high-skill occupational employment ${ }^{\text {a }}$

\begin{tabular}{lcccccc}
\hline & \multicolumn{7}{c}{ Probability of Scheduled Tribes occupational skill level } \\
\cline { 2 - 7 } & \multicolumn{2}{c}{ Low } & \multicolumn{2}{c}{ Middle } & High \\
\cline { 2 - 7 } Explanatory variable & dy/dx & SE & dy/dx & SE & dy/dx & SE \\
\hline & 0.0078 & 0.0190 & -0.0044 & 0.0187 & $-0.0034^{* *}$ & 0.0008 \\
ST public sector employment quota & & & & & & \\
& $-0.0263^{* *}$ & 0.0018 & $0.0207 * *$ & 0.0018 & $0.0056^{* *}$ & 0.0001 \\
Years of schooling & $-0.0028^{* *}$ & 0.0003 & $0.0023^{* *}$ & 0.0003 & $0.0005^{* *}$ & 0.0001 \\
Age & -0.0244 & 0.0178 & $0.0321^{*}$ & 0.0185 & $-0.0076^{* *}$ & 0.0017 \\
Male & 0.0001 & 0.0118 & 0.0054 & 0.0113 & $-0.0055^{* *}$ & 0.0013 \\
Married & -0.0431 & 0.0451 & 0.0367 & 0.0456 & 0.0064 & 0.0057 \\
Muslim religion b & $-0.1093^{* *}$ & 0.0171 & $0.1034^{* *}$ & 0.0156 & $0.0059^{* *}$ & 0.0028 \\
Other religion b & 0.0071 & 0.0521 & -0.0177 & 0.0511 & $0.0106^{* *}$ & 0.0025 \\
Urban sector & & & & & & \\
& 0.0234 & 0.0242 & -0.0267 & 0.0241 & $0.0033^{*}$ & 0.0019 \\
ST current year population share & 0.0116 & 0.0364 & -0.0019 & 0.0351 & $-0.0097^{* *}$ & 0.0019 \\
ST census population share & -0.0231 & 0.0336 & 0.0291 & 0.0331 & $-0.0061^{* *}$ & 0.0014 \\
SC public sector employment quota & $-0.0315^{* *}$ & 0.0095 & $0.0310^{* *}$ & 0.0093 & 0.0005 & 0.0009 \\
SC current year population share & 0.0199 & 0.0156 & -0.0176 & 0.0150 & $-0.0023^{* *}$ & 0.0011 \\
SC previous Census date population share & -0.0000 & 0.0000 & 0.0000 & 0.0000 & -0.0000 & 0.0000 \\
Total census population & $0.0009^{* *}$ & 0.0003 & $-0.0008^{* *}$ & 0.0003 & $-0.0001^{* *}$ & 0.0000 \\
Population density & -0.0069 & 0.0108 & 0.0040 & 0.0108 & $0.0029^{* *}$ & 0.0010 \\
Rural population share & $-0.0091^{*}$ & 0.0053 & $0.0089^{*}$ & 0.0052 & 0.0002 & 0.0003 \\
Public sector employees age 55-60 & 0.0027 & 0.0408 & -0.0103 & 0.0403 & $0.0076^{* *}$ & 0.0026 \\
Ln(state income per capita in previous year) & & & & & &
\end{tabular}

Notes: Marginal effects (dy/dx) of the explanatory variables on the probability of choosing high-, middle-, and lowskill occupations and standard errors are reported. The marginal effects are based on coefficient estimates from multinomial logit model, which are reported in Appendix Table A4, and the standard errors were adjusted for within state correlation across the four survey rounds. The total number of observations in the Scheduled Tribes sample is 110,295. Occupational skill is classified according to the 2004 National Classification of Occupations (NCO-2004); high-skilled occupations include professionals and associate professionals; middle-skill occupations include clerks, service workers, shop and market sale workers, agricultural and fishery workers, craft and related trades workers, and plant and machine operators and assemblers; low-skilled occupations include elementary occupations. See section 4.1 for more information on the specific occupations included in each skill category.

** Significant at 5-percent level; * Significant at 10-percent level.

a SC and ST indicate the populations of the Scheduled Castes and Scheduled Tribes, respectively.

${ }^{b}$ Hinduism is the reference category for religious affiliation. 
Table 4: The predicted average marginal effects of public sector employment quotas on the probability of low-, middle-, and high-skill occupational employment of the Scheduled Tribes by years of schooling ${ }^{\text {a }}$

ST public sector employment quota $X$ Years of schooling:

Probability of Scheduled Tribes occupational skill level

\begin{tabular}{|c|c|c|c|c|c|c|}
\hline 5 years & 0.0106 & 0.0174 & -0.0010 & 0.0166 & $-0.0096 * *$ & 0.0021 \\
\hline 10 years & 0.0134 & 0.0118 & 0.0195* & 0.0115 & $-0.0329 * *$ & 0.0073 \\
\hline 12 years & 0.0129 & 0.0089 & $0.0291 * *$ & 0.0103 & $-0.0420 * *$ & 0.0094 \\
\hline 16 years & $0.0076^{* *}$ & 0.0038 & $0.0317 * *$ & 0.0087 & $-0.0394 * *$ & 0.0098 \\
\hline
\end{tabular}

Notes: Marginal effects (dy/dx) of public employment quota on the probability of choosing high-, middle-, and lowskill occupations by years of schooling and standard errors are reported. The marginal effects are based on coefficient estimates from multinomial logit model, which are reported in Appendix Table A4, and the standard errors were adjusted for within state correlation across the four survey rounds. The total number of observations in the Scheduled Tribes sample is 110,295. Occupational skill is classified according to the 2004 National Classification of Occupations (NCO-2004); high-skilled occupations include professionals and associate professionals; middle-skill occupations include clerks, service workers, shop and market sale workers, agricultural and fishery workers, craft and related trades workers, and plant and machine operators and assemblers; low-skilled occupations include elementary occupations. See section 4.1 for more information on the specific occupations included in each skill category. ** Significant at 5-percent level; * Significant at 10-percent level.

${ }^{\mathrm{a}} \mathrm{ST}$ indicates the population of the Scheduled Tribes. 
Appendix Table - A1: Descriptive statistics of the Scheduled Castes population employed in high, middle, and low-skill occupations and the state environment in India by year ${ }^{\mathrm{a}}$

\begin{tabular}{|c|c|c|c|c|c|c|c|c|}
\hline \multirow[b]{3}{*}{ Individual-level variables } & \multicolumn{8}{|c|}{ Year } \\
\hline & \multicolumn{2}{|c|}{1983} & \multicolumn{2}{|c|}{1988} & \multicolumn{2}{|c|}{1994} & \multicolumn{2}{|c|}{1999} \\
\hline & Mean & SD & Mean & SD & Mean & SD & Mean & SD \\
\hline Low-skill occupation (0-1) & 0.60 & & 0.57 & & 0.59 & & 0.55 & \\
\hline Middle-skill occupation (0-1) & 0.38 & & 0.41 & & 0.39 & & 0.42 & \\
\hline High-skill occupation (0-1) & 0.02 & & 0.02 & & 0.02 & & 0.03 & \\
\hline Years of schooling (years) & 0.26 & 1.36 & 0.40 & 1.69 & 2.05 & 3.60 & 2.55 & 4.19 \\
\hline Age (years) & 35.76 & 12.15 & 35.67 & 12.25 & 36.05 & 12.06 & 36.46 & 12.09 \\
\hline Male $(0-1)$ & 0.71 & & 0.84 & & 0.73 & & 0.72 & \\
\hline Married (0-1) & 0.90 & & 0.88 & & 0.88 & & 0.87 & \\
\hline Muslim religion $(0-1)$ & 0.01 & & 0.01 & & 0.01 & & 0.01 & \\
\hline Other religion $(0-1)$ & 0.05 & & 0.06 & & 0.04 & & 0.08 & \\
\hline Urban sector $(0-1)$ & 0.22 & & 0.29 & & 0.25 & & 0.27 & \\
\hline \multicolumn{9}{|l|}{ State-level variables } \\
\hline SC public sector employment quota (\%) & 16.56 & 4.77 & 16.54 & 4.86 & 17.41 & 5.09 & 17.32 & 5.07 \\
\hline SC current year population share (\%) & 16.76 & 5.15 & 17.16 & 5.28 & 17.89 & 4.86 & 18.37 & 4.87 \\
\hline SC census population share (\%) & 16.60 & 5.17 & 16.59 & 5.35 & 17.60 & 4.88 & 17.49 & 4.95 \\
\hline ST public sector employment quota (\%) & 7.25 & 5.94 & 7.35 & 5.96 & 8.22 & 7.00 & 8.19 & 6.91 \\
\hline ST current year population share (\%) & 6.90 & 7.06 & 6.85 & 7.30 & 7.31 & 7.48 & 7.39 & 7.47 \\
\hline ST census population share (\%) & 6.90 & 7.04 & 6.82 & 7.23 & 7.29 & 7.44 & 7.35 & 7.37 \\
\hline Total census population (millions) & 57.95 & 29.83 & 63.93 & 34.75 & 74.00 & 37.94 & 82.55 & 44.00 \\
\hline Population density (n) & 316.83 & 162.32 & 311.81 & 159.91 & 390.18 & 190.92 & 379.26 & 185.09 \\
\hline Rural population share (\%) & 76.51 & 7.01 & 75.59 & 7.19 & 74.45 & 7.91 & 73.28 & 8.96 \\
\hline Public sector employees age 55-60 (\%) & 81.11 & 2.98 & 78.19 & 3.17 & 77.03 & 3.70 & 78.64 & 3.48 \\
\hline Income per capita in previous year (Rupees) & $1,059.37$ & 293.04 & $1,230.01$ & 346.99 & $53,905.13$ & $25,094.27$ & $72,730.40$ & $36,160.63$ \\
\hline Number of observations & 66,092 & & 52,599 & & 57,958 & & 26,296 & \\
\hline
\end{tabular}

Notes: Sample means and standard deviations are reported. Fraction of the population employed in high, middle, and low-skill occupations may not sum to one due to rounding. Occupational skill is classified according to the 2004 National Classification of Occupations (NCO-2004); high-skilled occupations include professionals and associate professionals; middle-skill occupations include clerks, service workers, shop and market sale workers, agricultural and fishery workers, craft and related trades workers, and plant and machine operators and assemblers; low-skilled occupations include elementary occupations. See section 4.1 for more information on the specific occupations included in each skill category. State income adjusted for inflation using the CPI-Industrial Worker in 2001 rupees. The states represented in our sample are Andhra Pradesh, Assam, Bihar, Gujarat, Haryana, Jammu-Kashmir, Karnataka, Kerala, Madhya Pradesh, Maharashtra, Orissa, Punjab, Rajasthan, Tamil Nadu, Uttar Pradesh and West Bengal.

Sources: National Sample Survey round 38, 43, 50, and 55 for the year 1983, 1987-1988, 1993-1994, and 1999-2000, respectively. Employment quota data are obtained from the Scheduled Caste and Scheduled Tribe Annual Commissioner's Report (1951-2000); current population share and population density data are from the Census of India, Registrar General; state per capita income data are based on the domestic product of states of India prepared by the Economic and Political Weekly Research Foundation.

${ }^{a}$ SC and ST indicate the populations of the Scheduled Castes and Scheduled Tribes, respectively. 
Appendix Table - A2: Descriptive statistics of the Scheduled Tribes population employed in high, middle, and low-skill occupations and the state environment in India by year ${ }^{\text {a }}$

\begin{tabular}{|c|c|c|c|c|c|c|c|c|}
\hline \multirow[b]{3}{*}{ Individual-level variables } & \multicolumn{8}{|c|}{ Year } \\
\hline & \multicolumn{2}{|c|}{1983} & \multicolumn{2}{|c|}{1988} & \multicolumn{2}{|c|}{1994} & \multicolumn{2}{|c|}{1999} \\
\hline & Mean & SD & Mean & SD & Mean & SD & Mean & SD \\
\hline Low-skill occupation (0-1) & 0.42 & & 0.40 & & 0.43 & & 0.43 & \\
\hline Middle-skill occupation (0-1) & 0.57 & & 0.58 & & 0.55 & & 0.54 & \\
\hline High-skill occupation (0-1) & 0.01 & & 0.02 & & 0.02 & & 0.03 & \\
\hline Years of schooling (years) & 0.19 & 1.22 & 0.38 & 1.66 & 1.67 & 3.33 & 2.04 & 3.80 \\
\hline Age (years) & 34.92 & 11.89 & 35.15 & 12.04 & 35.53 & 11.94 & 35.84 & 11.83 \\
\hline Male $(0-1)$ & 0.64 & & 0.80 & & 0.66 & & 0.63 & \\
\hline Married (0-1) & 0.90 & & 0.89 & & 0.90 & & 0.88 & \\
\hline Muslim religion (0-1) & 0.01 & & 0.02 & & 0.01 & & 0.01 & \\
\hline Other religion $(0-1)$ & 0.05 & & 0.06 & & 0.04 & & 0.08 & \\
\hline Urban sector $(0-1)$ & 0.11 & & 0.16 & & 0.11 & & 0.13 & \\
\hline State-level variables & & & & & & & & \\
\hline SC public sector employment quota (\%) & 14.26 & 4.02 & 14.24 & 3.94 & 14.02 & 4.19 & 13.85 & 4.14 \\
\hline SC current year population share (\%) & 13.33 & 4.32 & 13.92 & 4.09 & 14.68 & 3.99 & 15.23 & 4.00 \\
\hline SC census population share (\%) & 13.13 & 4.39 & 13.26 & 4.33 & 14.30 & 4.02 & 14.10 & 3.99 \\
\hline ST public sector employment quota (\%) & 12.43 & 6.36 & 12.53 & 6.25 & 14.45 & 7.31 & 13.69 & 7.19 \\
\hline ST current year population share (\%) & 14.03 & 7.39 & 13.96 & 7.58 & 14.59 & 7.43 & 14.00 & 7.34 \\
\hline ST census population share (\%) & 14.00 & 7.37 & 13.85 & 7.51 & 14.52 & 7.40 & 13.81 & 7.25 \\
\hline Total census population (millions) & 50.94 & 18.12 & 57.49 & 22.41 & 61.14 & 23.06 & 67.82 & 26.65 \\
\hline Population density $(\mathrm{n})$ & 221.01 & 135.53 & 226.53 & 136.74 & 260.62 & 157.25 & 265.23 & 154.16 \\
\hline Rural population share (\%) & 77.63 & 8.05 & 77.40 & 8.32 & 75.63 & 8.70 & 74.50 & 9.51 \\
\hline Public sector employees age $55-60$ (\%) & 81.05 & 3.64 & 78.05 & 3.62 & 76.00 & 5.12 & 76.83 & 4.59 \\
\hline Income per capita in previous year (Rupees) & $1,008.14$ & 251.93 & $1,135.16$ & 274.31 & $46,953.38$ & $27,578.13$ & $65,145.13$ & $41,649.48$ \\
\hline Number of observations & 36,873 & & 28,707 & & 30,024 & & 14,691 & \\
\hline
\end{tabular}

Notes: Sample means and standard deviations are reported. Fraction of the population employed in high, middle, and low-skill occupations may not sum to one due to rounding. Occupational skill is classified according to the 2004 National Classification of Occupations (NCO-2004); high-skilled occupations include professionals and associate professionals; middle-skill occupations include clerks, service workers, shop and market sale workers, agricultural and fishery workers, craft and related trades workers, and plant and machine operators and assemblers; low-skilled occupations include elementary occupations. See section 4.1 for more information on the specific occupations included in each skill category. State income adjusted for inflation using the CPI-Industrial Worker in 2001 rupees. The states represented in our sample are Andhra Pradesh, Assam, Bihar, Gujarat, Haryana, Jammu-Kashmir, Karnataka, Kerala, Madhya Pradesh, Maharashtra, Orissa, Punjab, Rajasthan, Tamil Nadu, Uttar Pradesh and West Bengal.

Sources: National Sample Survey round 38, 43, 50, and 55 for the year 1983, 1987-1988, 1993-1994, and 1999-2000, respectively. Employment quota data are obtained from the Scheduled Caste and Scheduled Tribe Annual Commissioner's Report (1951-2000); current population share and population density data are from the Census of India, Registrar General; state per capita income data are based on the domestic product of states of India prepared by the Economic and Political Weekly Research Foundation.

${ }^{a}$ SC and ST indicate the populations of the Scheduled Castes and Scheduled Tribes, respectively. 
Appendix Table - A3: Multinomial logit estimates of the probability the Scheduled Castes choosing low- and high-skill level occupations relative to the probability of choosing middleskill level occupations ${ }^{a, b}$

\begin{tabular}{|c|c|c|c|c|}
\hline \multirow[b]{3}{*}{ Explanatory variable } & \multicolumn{4}{|c|}{ Dependent variable } \\
\hline & \multicolumn{2}{|c|}{$\log \left(\mathrm{P}_{\text {Low }} / \mathrm{P}_{\text {Middle }}\right)$} & \multicolumn{2}{|c|}{$\log \left(P_{\text {High }} / P_{\text {Middle }}\right)$} \\
\hline & Coefficient & SE & Coefficient & SE \\
\hline SC public sector employment quota & -0.0399 & 0.0304 & $0.1477 * *$ & 0.0612 \\
\hline $\begin{array}{l}\text { SC public sector employment quota X Years of } \\
\text { schooling }\end{array}$ & -0.0009 & 0.0015 & -0.0026 & 0.0025 \\
\hline Years of schooling & $-0.1101 * *$ & 0.0220 & $0.3476 * *$ & 0.0426 \\
\hline Age & $0.0153 *$ & 0.0089 & $0.1539 * *$ & 0.0207 \\
\hline Age-squared & $-0.0004 * *$ & 0.0001 & $-0.0017 * *$ & 0.0003 \\
\hline Male & $-0.3429 * *$ & 0.0628 & $-0.7815^{* *}$ & 0.1339 \\
\hline Married & $0.1688^{* *}$ & 0.0587 & $-0.1781 * *$ & 0.0894 \\
\hline Muslim religion ${ }^{c}$ & $-0.5388 * *$ & 0.1479 & $0.7060 * *$ & 0.3497 \\
\hline Other religion ${ }^{c}$ & 0.0800 & 0.0972 & $0.2406 *$ & 0.1333 \\
\hline Urban sector & $-0.4440 * *$ & 0.1314 & $0.3554 * *$ & 0.0889 \\
\hline SC current year population share & -0.0047 & 0.0307 & $-0.1417 * *$ & 0.0498 \\
\hline SC census population share & 0.0308 & 0.0471 & $0.1773 * *$ & 0.0841 \\
\hline ST public sector employment quota & -0.0048 & 0.0254 & $0.0851^{*}$ & 0.0465 \\
\hline ST current year population share & 0.1713 & 0.1073 & -0.1333 & 0.1748 \\
\hline ST census population share & -0.0107 & 0.1307 & 0.2727 & 0.2752 \\
\hline Total census population & $0.0000 * *$ & 0.0000 & -0.0000 & 0.0000 \\
\hline Population density & 0.0004 & 0.0009 & 0.0024 & 0.0016 \\
\hline Rural population share & $-0.0382 * *$ & 0.0166 & $0.0671 *$ & 0.0391 \\
\hline Public sector employees age $55-60$ & $-0.0222 * *$ & 0.0096 & -0.0203 & 0.0216 \\
\hline Ln(state income per capita in previous year) & $-0.1369 * *$ & 0.0419 & 0.1080 & 0.1085 \\
\hline Constant & $5.2252 * *$ & 1.8649 & $-14.0247 * *$ & 4.1481 \\
\hline Maximized log-likelihood function & & -1396 & 5.61 & \\
\hline State fixed effects & & Ye & & \\
\hline Time fixed effects & & Ye & & \\
\hline Number of observations & & 202 & & \\
\hline
\end{tabular}

Notes: Coefficients and standard errors are reported. The standard errors were adjusted for within state correlation across the four survey rounds. Occupational skill is classified according to the 2004 National Classification of Occupations (NCO-2004); high-skilled occupations include professionals and associate professionals; middle-skill occupations include clerks, service workers, shop and market sale workers, agricultural and fishery workers, craft and related trades workers, and plant and machine operators and assemblers; low-skilled occupations include elementary occupations. See section 4.1 for more information on the specific occupations included in each skill category. ** Significant at 5-percent level; * Significant at 10-percent level.

${ }^{\text {a }}$ SC and ST indicate the populations of the Scheduled Castes and Scheduled Tribes, respectively.

${ }^{b}$ The probability of choosing low-, middle, and high-skill level occupations is denoted by $\mathrm{P}_{\text {Low }} \mathrm{P}_{\text {Middle }}$ and $\mathrm{P}_{\text {High }}$ respectively.

${ }^{\mathrm{C}}$ Hinduism is the reference category for religious affiliation 
Appendix Table - A4: Multinomial logit estimates of the probability the Scheduled Tribes choosing low- and high-skill level occupations relative to the probability of choosing middleskill level occupations ${ }^{a, b}$

\begin{tabular}{|c|c|c|c|c|}
\hline \multirow[b]{3}{*}{ Explanatory variable } & \multicolumn{4}{|c|}{ Dependent variable } \\
\hline & \multicolumn{2}{|c|}{$\log \left(\mathrm{P}_{\text {Low }} / \mathrm{P}_{\text {Middle }}\right)$} & \multicolumn{2}{|c|}{$\log \left(P_{\text {High }} / P_{\text {Middle }}\right)$} \\
\hline & Coefficient & SE & Coefficient & SE \\
\hline ST public sector employment quota & 0.0291 & 0.0853 & $-0.2338 * *$ & 0.0517 \\
\hline $\begin{array}{l}\text { ST public sector employment quota X Years of } \\
\text { schooling }\end{array}$ & 0.0020 & 0.0013 & $0.0030 * *$ & \\
\hline Years of schooling & $-0.1375 * *$ & 0.0199 & $0.3019 * *$ & 0.0217 \\
\hline Age & $0.0312 * *$ & 0.0063 & $0.1499 * *$ & 0.0212 \\
\hline Age-squared & $-0.0006 * *$ & 0.0001 & $-0.0017 * *$ & 0.0002 \\
\hline Male & -0.1207 & 0.0811 & $-0.5476 * *$ & 0.1302 \\
\hline Married & -0.0072 & 0.0526 & $-0.3667 * *$ & 0.0855 \\
\hline Muslim religion ${ }^{c}$ & -0.1857 & 0.2039 & 0.3695 & 0.3897 \\
\hline Other religion ${ }^{c}$ & $-0.4849 * *$ & 0.0749 & 0.2445 & 0.1769 \\
\hline Urban sector & 0.0468 & 0.2339 & $0.7197 * *$ & 0.1566 \\
\hline ST current year population share & 0.1102 & 0.1090 & $0.2530 * *$ & 0.1262 \\
\hline ST census population share & 0.0389 & 0.1626 & $-0.6374 * *$ & 0.0926 \\
\hline SC public sector employment quota & -0.1126 & 0.1508 & $-0.4386 * *$ & 0.0823 \\
\hline SC current year population share & $-0.1415^{* *}$ & 0.0425 & -0.0094 & 0.0562 \\
\hline SC census population share & 0.0868 & 0.0698 & $-0.1271 *$ & 0.0659 \\
\hline Total census population & -0.0000 & 0.0000 & -0.0000 & 0.0000 \\
\hline Population density & $0.0040 * *$ & 0.0015 & $-0.0051 * *$ & 0.0020 \\
\hline Rural population share & -0.0272 & 0.0487 & $0.1868^{* *}$ & 0.0704 \\
\hline Public sector employees age $55-60$ & $-0.0408^{*}$ & 0.0239 & 0.0011 & 0.0192 \\
\hline Ln(state income per capita in previous year) & 0.0229 & 0.1833 & $0.5138 * *$ & 0.1717 \\
\hline Constant & 5.8166 & 5.9063 & $-11.4080 *$ & 6.2336 \\
\hline Maximized log-likelihood function & & -767 & .97 & \\
\hline State fixed effects & & & & \\
\hline Time fixed effects & & & & \\
\hline Number of observations & & 110 & & \\
\hline
\end{tabular}

Notes: Coefficients and standard errors are reported. The standard errors were adjusted for within state correlation across the four survey rounds. Occupational skill is classified according to the 2004 National Classification of Occupations (NCO-2004); high-skilled occupations include professionals and associate professionals; middle-skill occupations include clerks, service workers, shop and market sale workers, agricultural and fishery workers, craft and related trades workers, and plant and machine operators and assemblers; low-skilled occupations include elementary occupations. See section 4.1 for more information on the specific occupations included in each skill category. ** Significant at 5-percent level; * Significant at 10-percent level.

${ }^{\text {a }}$ SC and ST indicate the populations of the Scheduled Castes and Scheduled Tribes, respectively.

${ }^{b}$ The probability of choosing low-, middle, and high-skill level occupations is denoted by $\mathrm{P}_{\text {Low }} \mathrm{P}_{\text {Middle }}$ and $\mathrm{P}_{\text {High }}$ respectively.

${ }^{\mathrm{C}}$ Hinduism is the reference category for religious affiliation. 